\title{
A linguagem na análise fenomenológica do pensamento
}

\section{Language in phenomenological analysis of thought}

\section{Dario Teixeira}

Professor adjunto da Universidade Federal Rural do Rio de Janeiro (UFRuralRJ), professor colaborador da Pós-Graduação em Filosofia da Universidade Federal do Rio de Janeiro (UFRJ), Rio de Janeiro, RJ - Brasil, e-mail: darioalvesteixeira@gmail.com

\section{Resumo}

No presente artigo pretendo mostrar, em sua primeira seção, que há, para Husserl, uma acepção em que pensamentos são essencialmente linguísticos, mas que nem por isso ele admite que a análise linguística da estrutura composicional de sentenças seja uma condição suficiente para a especificação do pensamento expressado por elas. Argumentarei então, na segunda seção, que Husserl rejeita a simples identificação entre o teor de significação proposicional expressado e a significação linguística da sentença enunciada, mas que mesmo assim ele reconhece um tipo determinado de análise de enunciados como uma condição necessária da análise do pensamento e, por conseguinte, de sua intencionada morfologia das significações. Nesse 
sentido, a abordagem fenomenológica de pensamentos consiste em uma forma de sentencialismo moderado.

Palavras-chave: Fenomenologia. Husserl. Pensamento. Linguagem. Sentencialismo moderado.

\section{Abstract}

In these paper I intend to show that there is a sense in which is right to say that Husserl thinks that thoughts must be essentially linguistic, although he still sustains that the linguistic analysis of the compositional structure of the sentence can not be a sufficient condition to specify the structure of the expressed thought. I will argue that Husserl has good reasons to refuse to identify the propositional content with the linguistic meaning of a sentence, but even then he assumes that a certain kind of anlysis of statement is a necessary condition to the analysis of thought and therefore to their intended morphology of meaning. To sum up, the fenomenological approach of thoughts consists in a form of weak sentencialism.

Keywords: Phenomenology. Husserl. Thought. Language. Weak Sentencialism.

\section{Introdução}

Uma formulação sumária acerca do marco característico da filosofia contemporânea consiste em mencionar uma mudança de orientação da via das ideias (the way of ideas) para a via das palavras (the way of words), em suma, uma reorientação para a axial noção antimentalista de significação (the semantic ascent) e, particularmente, para a noção de pensamento na acepção objetiva, de viés fregeano, de teor de significação proposicional de sentenças (the linguistic turn). Diante do primado da representação e da consciência na época moderna, haveria um primado da significação e da linguagem em nossa época filosófica que se atestaria, por exemplo, sob a forma mais estrita da filosofia analítico-linguística, mas também sob a forma hermenêutica ou pragmática, tendo todas em comum, aparentemente, pelo menos as mesmas rejeições à centralidade da noção internalista de subjetividade, ao programa de análise psicológica da significação proposicional e ao primado da questão 
epistemológica acerca da relação entre a subjetividade do ato de conhecer e a objetividade do conteúdo do conhecimento.

Desde uma tal perspectiva, costuma-se então estimar que a fenomenologia, pelo menos a husserliana, teria ficado aquém, se não da "ascensão semântica", então ao menos da "virada linguística" da filosofia contemporânea, seja porque não se emancipou do esquema sujeito-objeto sob o qual a nova noção central de significação seria inevitavelmente distorcida pelas únicas alternativas de sua subjetivação ou objetivação (TUGENDHAT, [1970] 1977), seja porque generalizou essa nova noção até torná-la indeterminada por não reconhecer seu radicamento exclusivamente nos comportamentos linguísticos (DUMMETT, 1993, especialmente cap. 11), ou porque até reconheceu tal radicamento no veículo linguístico, mas então concebeu a linguagem ainda em termos monológicos e puramente instrumentais que seriam incompatíveis com seu caráter constitutivo de meio sociocultural inexcedível da interação humana (APEL, [1955] 1973, especialmente seção II). No melhor dos casos se concede a Husserl o insight genético bastante tardio, e também pouco elaborado, concernente ao caráter intrinsecamente linguístico do pensamento e ao caráter historicamente intersubjetivo da linguagem, mas apenas para enfatizar, por contraste, sua persistente visão estática inicial acerca do caráter improdutivo da linguagem enquanto mera manifestação secundária dos pensamentos que, por sua vez, consistiriam na mera reprodução em conceitos de um estrato mais originário da experiência (WELTON, 1983, especialmente cap. 10). Também não é incomum que, exatamente em sentido inverso, simplesmente se denuncie excessivas concessões husserlianas a um fio condutor linguístico desviante no procedimento de análise das vivências de pensamento em geral (DE PALMA, 2008) e se tente promover então uma reafirmação das virtudes da análise direta do teor de significação proposicional ou pensamento sobre a base psicológica da percepção interna dos atos de pensar (ROLLINGER, 2003).

Sem pretender fazer qualquer balanço dos méritos e ônus relativos da abordagem linguística diante da abordagem psicológica, gostaria tão somente de questionar aqui a simplicidade do juízo firmado sobre a análise fenomenológica, aliás, husserliana do teor de significação ou pensamento em qualquer dessas versões extremadas. Assumindo como pano de fundo esse quadro panorâmico sumário que apresenta simplificadamente alternativas opostas bem marcadas, pretendo apenas abordar, com base diretamente em textos de Husserl, as duas questões seguintes: (I) qual relação Husserl afinal concebe como vigorando entre pensamento e linguagem? (II) qual relação Husserl afinal concebe como vigorando entre análise do pensamento e análise 
da linguagem? Minhas respostas a essas questões pretenderão, sobretudo, indicar alguns princípios que possam guiar uma leitura mais íntegra e consistente da obra madura de Husserl, inaugurada por suas Investigações lógicas, pelo menos quando se tratar de questões concernentes à análise do pensamento nessa acepção objetiva de teor de significação proposicional.

Nesse sentido, antecipo que, na primeira seção, responderei à primeira questão argumentando não só que Husserl se compromete expressamente com a dependência, o paralelismo ou isomorfismo entre pensamento e linguagem, como também que essa é, na verdade, a posição mais consequente que cabe a ele assumir, como ficará claro não só por suas declarações expressas através de toda sua obra, mas também pela reconstrução que farei da ordem de ideias de uma passagem privilegiada do $\$ 35$ da primeira das Investigações lógicas - a qual, curiosamente, é muito explorada pelos seus intérpretes para afirmar de maneira sumária exatamente o contrário do que pretendo defender aqui, a saber, para afirmar a autonomia do pensamento, aliás, do teor de significação com respeito à linguagem.

Essa minha interpretação deve suscitar imediatamente a questão seguinte: dada então a dependência, paralelismo ou isomorfismo entre pensamento e linguagem, então por que a análise fenomenológica do pensamento não é afinal uma pura e simples análise linguística da sentença que expressa esse teor de significação proposicional? Quanto a essa segunda questão, minha intenção é a de mostrar, na segunda seção, que a análise da linguagem é, com efeito, considerada por Husserl como uma condição necessária da análise fenomenológica da significação, mas que de modo algum ela pode ser uma condição suficiente; em outras palavras, pretendo mostrar que o teor de significação proposicional ou pensamento enunciado não pode ser identificado sem mais com a significação linguística da sentença que o expressa, mesmo que a significação de enunciados seja ainda uma via privilegiada para a abordagem do pensamento nessa acepção objetiva de teor de significação proposicional. Nas considerações finais, tento então indicar algumas direções de desenvolvimento dessa concepção de análise fenomenológica do pensamento, sobretudo no que concerne ao estabelecimento das bases para a realização do projeto husserliano de uma gramática lógica ou morfologia das significações. 


\section{I}

\section{O pensamento consiste na capacidade de conceber por meio de símbolos}

Não é incomum encontrarmos afirmações de que, concebido nas Investigações lógicas enquanto entidade de caráter ideal ou abstrato, o teor de significação mantém uma relação extrínseca com a linguagem enquanto mero meio contingente para sua eventual manifestação. David Bell (1990, p. 106), por exemplo, marca sua posição nos seguintes termos: "Husserl rejeita a pretensão de que haja uma relação essencial ou explanatória entre a natureza de expressões linguísticas, ou os fenômenos lingüísticos em geral, e a natureza das "significações em si mesmas"'. Falando ainda das Investigações lógicas, Jocelin Benois (2003, p. 17) também escreve o seguinte: "Tanto para Husserl quanto para Frege, o tipo de objetividade que está aqui em questão [sc. a objetividade do pensamento] se encontra, entretanto, para além do discurso e da efetividade de qualquer proferimento". Até mesmo um intérprete de Husserl tão sofisticado quanto Gianfranco Soldati (2008, p. 63) afirma categoricamente o seguinte: "Embora a comunicação lingüística desempenhe um papel central no entendimento que Husserl tem da significação, Husserl não compartilha a opinião difundida de que significações são essencialmente lingüísticas". E o próprio Soldati (2008, p. 63, nota 4) nos explica tudo o que supostamente estaria em jogo ao se tratar significações como essencialmente linguísticas:

A tese de que significações são essencialmente lingüísticas pode ser entendida em mais de um sentido. Em um sentido metafísico, ela pode querer dizer que significações dependeriam da linguagem para sua existência: não haveria quaisquer significações que não estivessem lingüisticamente expressadas (no caso de uma dependência forte) ou que não pudessem vir a ser expressadas (no caso de uma dependência fraca). Em um segundo sentido, agora epistêmico, significações seriam lingüísticas, na medida em que elas nos seriam acessíveis tão somente através da linguagem. A articulação lingüística seria então uma condição para apreender significações.

Com base nessa explicação do conteúdo da tese de que significações seriam essencialmente linguísticas, Soldati (2008, p. 63) afirma então conclusivamente: "Husserl não sustenta fundamentalmente nenhuma dessas duas posições".

Rev. Filos., Aurora, Curitiba, v. 22, n. 31, p. 319-346, jul./dez. 2010 
Deverei aqui argumentar diretamente contra esses intérpretes e em defesa pelo menos do que Soldati chamou de "sentido epistêmico" da tese de que significações são essencialmente linguísticas, porquanto acederíamos a elas por meio da compreensão de simbolismos. Não tratarei aqui do que Soldati chamou de "sentido metafísico" dessa tese, mas deixo registrado que ao rejeitá-la sem mais podemos ficar bem próximos de tomar em sentido literal o que tinha originalmente um sentido figurado, a saber, a metáfora fregeana de um "terceiro reino" de entidades nem psíquicas (portanto, objetivas) nem físicas (portanto, não-reais); ${ }^{1}$ isso por si só não deveria ser nada de escandaloso, afinal, apenas um irrefletido naturalismo empirista explicaria que, nesse ponto, tivéssemos uma reação automática de repulsa à mera sugestão de que talvez o modo correto de conceber o elemento categorial do pensamento consistisse justamente em interpretá-lo em termos de Ideias quasi-platônica ou, pelo menos, de Espécies quasi-aristotélica. Questiono de saída apenas se essa afirmação de que significações são entidades autônomas em relação à linguagem, feita assim sem maiores qualificações, não seria antes um princípio de leitura desvirtuador da nossa compreensão quando aplicada à teoria da significação de Husserl e ao modo fenomenológico de análise de pensamento que explicitamente se compromete com o esclarecimento do vínculo intrínseco entre significações e atos de pensamento e de fala, e isso literalmente em termos da relação de instanciação de espécies por seus casos particulares (HUSSERL, [1900a] 1992a, 2º $, \S 1, \mathrm{~B} 109)$, vale dizer, como acredito ser correto interpretar (TEIXEIRA, 2007), em termos da relação entre meios de referência determinados considerados ideativamente e o exercício em ato dessa referência segundo esses meios determinados na efetuação de vivências intencionais, primariamente na efetuação de atos signitivos, como deverei argumentar aqui.

De todo modo, é claro que esses intérpretes mencionados não são leitores levianos da obra de Husserl, mas antes afirmam a tese da autonomia das significações se amparando em geral na célebre argumentação antipsicologista de Husserl e, particularmente, tanto na primeira quanto na segunda das

1 Esse não é o caminho tomado por Soldati (1994, especialmente capítulo 5, §IX e capítulo 6, §III) que, muito ao contrário, pretende reconstruir a posição de Husserl ao eliminar a tese da idealidade da significação e explicar significações em termos simplesmente de qualidades disposicionais de eventos psíquicos, o que me parece realmente engenhoso como interpretação da tese autenticamente husserliana de que significações são conteúdos intencionais in specie de atos, ainda que eu não veja porque essa interpretação deva excluir a tese da idealidade. De todo modo, nesse ponto não conflitarei com Soldati, antes explorarei suas interpretações um pouco contra ele mesmo.

Rev. Filos., Aurora, Curitiba, v. 22, n. 31, p. 319-346, jul./dez. 2010 
Investigações lógicas. E até mais especificamente, se pedirmos a esses intérpretes que apresentem alguma passagem textual específica que ateste essas suas afirmações eles nos remeterão confiantes, via de regra, ${ }^{2}$ ao $§ 35$ da primeira das Investigações lógicas, intitulado: "significações 'em si' e significações expressadas", onde Husserl faz as duas seguintes afirmações:

(I) "Segundo sua própria natureza, não há qualquer conexão necessária entre as unidades ideais que factualmente funcionam como significações e os signos aos quais elas estão vinculadas [...]" (HUSSERL, [1900a] 1992a, $1^{\circ}, \S 35$, p. B104; grifo meu);

(II) "As significações formam um conjunto idealmente fechado de objetos universais para os quais é contingente o vir a ser pensado ou expressado. Há, com efeito, incontáveis significações que, segundo o sentido habitualmente relacional deste termo, são significações meramente possíveis, enquanto nunca são expressas e, por força das limitações das capacidades cognitivas humanas, podem nunca ser expressas" (HUSSERL, [1900a] 1992a, 1º $\S 35$, B105; grifo meu).

Essas são sem dúvida afirmações inequivocamente categóricas, de modo que caberia perguntar se precisamos de algo mais para fazer coro nesse ponto com os intérpretes de Husserl que afirmam a autonomia das significações em relação à linguagem e, mais especificamente, em relação à nossa compreensão de simbolismos. Bem, eu diria que precisamos sim de muito mais!

Por exemplo: na primeira passagem, Husserl faz considerações, como ele o diz expressamente, acerca da própria natureza das significações e

2 Desde a marcante interpretação de Derrida (que se encontra tanto em seu longo texto de introdução a um manuscrito de Husserl de 1936, traduzido por ele sob o título: L'Origine de la Géométrie, 1962, quanto em seu ensaio sobre a primeira das Investigações lógicas, intitulado La Voix et le Phénoméne, 1967), não é incomum que se explore também, sobretudo, o §8 intitulado: "As expressões na vida solitária da alma”, para argumentar que, ao caracterizar a função expressiva como conceitualmente distinta da função comunicativa, Husserl se ampararia em uma separação ontológica entre o signo, enquanto realidade da linguagem praticada intersubjetivamente, e a significação, enquanto idealidade que, no monólogo, se revela livre de radicamentos ônticos ou mundanos. Reagir a essa interpretação requereria mostrar que a comunicação desempenha papel central na concepção husserliana da linguagem, mas me restrinjo aqui preliminarmente a tão somente tentar mostrar que a linguagem desempenha papel central na concepção husserliana de significação, isto é, argumento aqui apenas em favor preliminarmente do vínculo intrínseco entre teor de significação (pensamento) e signo (linguagem), no sentido de tentar estabelecer que, na fenomenologia, a análise do pensamento não é independente sem mais da análise da linguagem. 
não acerca de nosso modo de relação com significações. Ademais, o que ele diz então acerca das significações é que elas são sim idealidades, mas que funcionam factualmente como significações de signos, ainda que não mantenham uma relação necessária com o signo particular que factualmente a veicula, o que me parece poder, e dever, ser entendido bem trivialmente como consistindo na afirmação de que, por exemplo, a significação < cachorro> é tal que nada nela a vincula internamente com a expressão "cachorro", até porque essa significação pode vincular-se também à expressão inglesa $d o g$ ou à expressão alemã Hund, bem como pode vincular-se à expressão portuguesa "cão" ou (por que não?) à palavra "mesa" - afinal, nada o exclui por princípio. O que quero dizer é que o que está sendo afirmado aí nada mais seria do que a bem conhecida tese da arbitrariedade do signo linguístico (HUSSERL, [1900b] 1992b, 6 , §26, B92: “a significação não pode, por assim dizer, pender no ar, mas para aquilo que ela significa é completamente indiferente qual é o signo do qual dizemos que ela é a significação"), que, diferentemente, de outros tipos de signos, não mantém com o que significa qualquer relação natural, seja por associação, como no caso de signos indicativos, seja por semelhança, como no caso de signos icônicos, tal como nos ensinam justamente os parágrafos iniciais dessa primeira das Investigações lógicas, intitulada "Expressão e Significação". Em suma, essa passagem, tão explorada pelos intérpretes para afirmar a autonomia do teor de significação do pensamento diante da linguagem, pode ser lida mais modestamente como uma reafirmação do convencionalismo de Hermógenes contra o naturalismo de Crátilo, tal como fizera o próprio Platão no seu diálogo clássico sobre o tema.

Já na segunda passagem citada em apoio da tese da autonomia da significação, Husserl de fato trata então da relação das significações para com nossas capacidades de pensar e expressar. Mas o que ele diz então de propriamente pregnante a esse respeito? Por um lado, Husserl diz expressamente que em seu sentido habitualmente relacional, isto é, em seu sentido de significação para atos de pensar ou significação de expressões linguísticas, essas significações são meramente possíveis, vale dizer, são significações tais que em si mesmas, ou por princípio, elas são sim, como ele o diz, objetos universais, mas isso na acepção de serem conteúdos possíveis de atos de pensar e de expressar, o que, segundo a teoria oficial de Husserl nessa obra, quer dizer justamente que há uma relação sistemática entre significações e atos mentais ou linguísticos, a saber, a relação que vigora entre um universal e seus casos particulares possíveis que o exemplificam. Por outro lado, Husserl diz ainda nessa passagem que significações, de fato, podem até mesmo nunca ser pensadas ou 
expressadas, mas isso então apenas em virtude de limitações do lado de nossas faculdades cognitivas ou expressivas, mas não em virtude das próprias significações enquanto tais não serem pensáveis ou expressáveis; até porque, como acabamos de ver, se há um sentido em que podemos dizer plausivelmente que existem significações ideais é no sentido de que elas são conteúdo possível de atos de pensar e falar, o que não diz nada a respeito desses atos serem ou não efetuáveis de fato, posto serem os atos apenas possíveis eventos psíqui$\cos$ reais sujeitos às condições restritivas da realidade psíquica. Em suma, parece-me trivial dizer que pode de fato ser inexequível efetuar certos atos de pensamento ou de expressão que poderiam por princípio ter por conteúdo algum teor determinado de significação (admitimos isso sem problema com respeito a crianças ou a pessoas em geral com capacidades intelectuais não suficientemente amadurecidas), por exemplo, a significação que consistiria na conjunção de todas as verdades aritméticas, até porque essa conjunção seria tão infinita quanto a própria série dos números, enquanto nossa capacidade cognitiva e expressiva é finita ou sofre de limitações, tais como as relativas a nossa memória.

Acredita-se estar em jogo nessa tese da autonomia da significação não apenas uma questão hermenêutica acerca da melhor compreensão da posição de Husserl, mas antes uma questão de ordem sistemática que visa a garantir, com tal autonomia, a objetividade do teor de significação proposicional do pensamento que teria nas expressões linguísticas apenas um meio contingente para sua eventual manifestação. Mas se o ponto em questão está em garantir, por meio do caráter não linguístico do teor de significação, o seu caráter epistemicamente objetivo, então me parece que se diz aí mais do que é necessário. O que se pretende mostrar é que o teor de significação é independente de qualquer forma linguística particular e de qualquer efetivo proferimento particular, mas o que se acaba por argumentar é que esse teor de significação seria independente da linguagem simpliciter, tout court, überhaupt, sem mais. Que o teor de significação seja o conteúdo de sentido possível de atos mentais e linguísticos não precisa afetar em nada sua objetividade, mas antes apenas especifica um tipo de constrangimento epistêmico que, pelo menos para nós, sujeitos cognoscentes finitos, é requerido como condição de inteligibilidade de nosso acesso a "pensamentos" objetivos; em outras palavras: para nós, ter pensamentos consiste em ser capaz de compreender o teor de significação determinado de enunciados.

Contudo, não preciso argumentar aqui apenas polemicamente, pois posso simplesmente tomar em conta o contexto geral desse próprio $\$ 35$ e, 
então, tornar patente de maneira direta as relações vigentes entre o teor de significação objetivo, os atos de pensar subjetivos e, enfim, a linguagem. Como pretendo ter acabado de mostrar, Husserl argumenta que, embora não seja essencial para a noção de significação que ela seja concebida como aquilo que é pensado ou expressado, mesmo assim ela deve ser concebida pelo menos como o que é conteúdo possível de atos de pensar. Agora pretendo mostrar que o argumento de Husserl também estabelece que atos de pensar não são independentes da linguagem; em outras palavras, o argumento de Husserl estabelece que a significação idealmente objetiva é aquilo que só pode vir a ser realmente um pensamento na medida em que for expressável e que ela só é expressável porque já tem o tipo de constituição própria requerida para tanto, a saber, porque a significação já é um possível modo determinado de referência objetal, segundo o qual um ato fundado em meros simbolismos pode ser o pensamento sobre algo determinado. Em outras palavras: a significação ideal só é expressável porque ela já é um modo possível de efetuação daquele tipo de ato que Husserl chama de "ato signitivo" (HUSSERL, [1900b] 1992b, $6^{\mathrm{o}}, \S 8, \mathrm{~B} 33$, nota) e que são atos que fazem referência meramente simbólica a alguma objetalidade, e isso por contraste com aquele outro tipo de ato, chamado de "ato intuitivo", e que são atos que apresentam como dada a própria objetalidade intencionada. O argumento de Husserl - bastante singelo e talvez por isso menosprezado - a esse respeito é o seguinte.

No próprio §35 da primeira das Investigações lógicas, Husserl começa por ponderar que significações em si se tornam para nós, ou se realizam em nós, através da formação de conceitos, isto é, na medida em que formamos em nós uma capacidade real de conceber de certa maneira como são as coisas, isto é, uma capacidade de pensar discursivamente, vale dizer, conceitualmente. Atestando isso, Husserl escreve: "todo caso de uma nova formação de conceitos nos mostra como se torna real [em nós] uma significação anteriormente ainda não realizada" ([1900a] 1992a, §35, B104-105; grifo meu). Exatamente na sequência de uma passagem que já citei em favor da tese da autonomia do pensamento que estou agora questionando, Husserl então claramente estabelece que nós formamos esses conceitos, ou desenvolvemos a capacidade de pensar conceitualmente, justamente por meio do manejo de simbolismos, isto é, em atos fundados sobre signos; em suma, formamos conceitos ao nos tornarmos aptos a efetuar atos signitivos enquanto modos determinados de fazer referência meramente simbólica a algo. Quanto a isso, Husserl escreve: "segundo sua própria natureza, não há qualquer conexão necessária entre as unidades ideais que factualmente funcionam como

Rev. Filos., Aurora, Curitiba, v. 22, n. 31, p. 319-346, jul./dez. 2010 
significações e os signos aos quais elas estão vinculadas, signos estes através dos quais essas significações se realizam na vida psíquica humana" ([1900a] 1992a, §35, B104; grifo meu). Eu pergunto então: qual a conclusão pertinente a se tirar dessas duas premissas? A conclusão que se impõe a meu ver é a de que, para nós, significações ideais consistem em capacidades conceituais segundo as quais podemos formar pensamentos determinados e que o desenvolvimento da capacidade de pensar conceitualmente tem por meio próprio os signos linguísticos que aprendemos a empregar, de maneira que dominar um conceito é ser capaz de efetuar um ato signitivo que consiste em uma maneira determinada de fazer referência simbólica a alguma objetalidade. Em outras palavras, acedemos a significações através da formação de conceitos; a formação de conceitos se funda sobre o domínio de signos; portanto, as significações, que são nossos meios conceituais de pensar determinadamente, estão radicadas em nossa compreensão de simbolismos; em suma, a linguagem é o meio próprio ou veículo intrínseco do pensamento discursivo.

Enfim, Husserl defende aqui ([1900b] 1992b, B14s.) a tese básica de que as vivências signitivas são aquelas portadoras primárias e exclusivas da significação própria que consiste no modo específico de alguma vivência efetuar-se como referência determinada a alguma objetalidade de certo tipo. Para Husserl, pensamentos são nossos modos discursivos, vale dizer, por aplicação de conceitos, de fazermos referência determinada a objetos e estados de coisas, de maneira que cada ato de pensar consiste na efetuação de uma vivência signitiva segundo um meio de referência determinado, aliás, segundo o que chamamos então de "sua significação". Em outras palavras, cada ato de pensar consiste em pôr em ação nossas capacidades conceituais de presumir simbolicamente que as coisas são tais ou quais, independentemente de podermos, ou de sequer precisarmos, chegar a identificar na experiência o objeto designado ou de verificar como sendo vigente no mundo o estado de coisas asserido - em suma, independentemente de ser ou não verdadeiro o teor de significação proposicional do pensamento enunciado. No §4 da sexta das Investigações lógicas ([1900b] 1992b, B14s.), Husserl argumenta que uma percepção pode dar ensejo a diferentes juízos perceptivos, mas que toda significação é própria tão somente ao ato judicativo que articula conceitualmente de algum modo esse substrato sob uma forma expressiva e, assim, faz referência simbólica determinada a alguma objetalidade; em tudo isso, a percepção pode ser constante e a enunciação variar ou a percepção pode variar e a enunciação se manter constante, bem como a percepção pode faltar de todo sem que em nenhum desses casos a significação e, respectivamente, a 
compreensão da enunciação seja afetada. Em suma, a significação é própria ao pensamento discursivo e é função de nossa compreensão de simbolismos, o que pode ter lugar mesmo na ausência completa de intuições concernentes à objetalidade intencionada.

Mesmo bastante tardiamente, isto é, na sua Lógica formal e transcendental, de 1929, Husserl mantém sua pergunta original das Investigações lógicas de 1900 acerca do tipo de vivência apta a desempenhar a função de portadora primária da significação, e ergue ainda o mesmo requerimento de que tal vivência precisaria ser tal que em todas as suas efetuações ela fosse expressiva, isto é, fosse a vivência signitiva de apreensão ou emprego com compreensão de simbolismos. De maneira direta, ele indaga: "qual tipo de essência geral uma vivência de consciência precisa ter a fim de poder se apresentar na função de significação?” ([1929] 1992c, §4, p. [22]). E então, qualificando tal tipo de vivência como a vivência de pensar, Husserl ([1929] 1992c, $\S 4$, p. [22-23]) estabelece o mesmo requerimento que acabei de especificar:

Coloca-se aqui o problema difícil e relevante de promover uma demarcação essencial do pensar numa acepção sumamente geral [...] e, com efeito, seguindo a intelecção de que, generalizadamente, em todas as particularizações desse 'pensar' necessitam formar-se expressões para as quais essas particularizações seriam as doadoras de significação.

Nesse contexto, podemos ler então algo de ainda mais inequívoco a esse respeito, quando Husserl ([1929] 1992c, §3, p. [22]) escreve:

Com efeito, sustentamos também a universalidade do recobrimento entre linguagem e pensamento. Isso agora designa então para nós dois reinos paralelos mutuamente correspondentes como sendo o reino de expressões lingüísticas possíveis (discursividade) e o reino de sentidos possíveis, de intenções de significação possivelmente expressáveis. Em sua entrelaçada unidade intencional, esses reinos da expressão possível e do sentido possível resultam no reino dual da discursividade em ato e concreta, plena de sentido.

É inequívoca, então, a assunção por parte de Husserl de uma dependência, paralelismo ou isomorfismo entre pensamento e linguagem, ainda que, em nome de razões sistemáticas de sua análise do elemento categorial do pensamento, ele metodicamente se exima de modo recorrente de se ocupar, em separado, das questões concernentes aos aspectos propriamente linguísticos do 
pensamento ([1917-1918] 1996, §15a, p. 66; [1929] 1992c, §5, p. [24]; Anexo I, p. [259]; [1939] 1985, §50b, p. 247, 248; §53, p. 266).

\section{II}

\section{A análise de pensamento tem por base a efetuação de enunciações}

Tal como anunciado, essa posição deve, porém, suscitar imediatamente a seguinte questão: dada a dependência, o paralelismo ou a isomorfia entre pensamento e linguagem, então por que a análise fenomenológica do teor de significação proposicional não é afinal uma pura e simples análise linguística de sentenças que expressam pensamentos? O modelo mais bem determinado de tal análise linguística de pensamento se encontra no programa de tornar inteligível o que é ter pensamentos através da explicação do que é conhecer os modos convencionais de emprego correto de expressões de nossa linguagem, vale dizer, se encontra implicado na própria pretensão da filosofia analítico-linguística de poder especificar exaustivamente o teor de pensamento expressado em termos exclusivamente da significação linguística da sentença que o expressa. Esse modelo analítico-linguístico de consideração do pensamento já foi batizado de "sentencialismo" e se deixa apresentar nos seguintes termos: a estrutura de pensamentos corresponde à estrutura das sentenças que os expressam e, assim, a estrutura de sentenças deve valer como modelo de análise da estrutura de pensamentos (DUMMETT, [1984] 1986). Tomando por referência esse modelo, podemos então reformular a pergunta inicial do presente parágrafo: como Husserl se situaria frente a esse modelo sentencialista de análise de pensamento? Não creio que tenhamos alguma razão para dizer que Husserl rejeita sem maiores qualificações o sentencialismo, o que também não quer dizer que ele o assuma sem maiores qualificações; enfim, uma resposta aqui depende justamente de determinar quais qualificações seriam relevantes para que a tese sentencialista fosse compatível com as demais teses características da fenomenologia husserliana.

Se for correta minha avaliação de que a tese sentencialista seria a conclusão que tem por premissas a tese do isomorfismo de pensamento e linguagem e a tese linguística da identidade do pensamento expressado e da significação linguística da sentença que o expressa, então a rejeição, ainda que qualificada, do sentencialismo deverá pressupor a rejeição de pelo menos uma dessas premissas. Visto que Husserl assume a tese do isomorfismo, então 
qualquer rejeição do sentencialismo passaria por sua rejeição da tese linguística da identidade entre teor de significação do pensamento e significação linguística da sentença, donde decorre a pretensão questionável de que unicamente a forma linguística da sentença seria suficiente para especificar o teor de significação proposicional ou pensamento enunciado. Com efeito, se eu falei de uma rejeição qualificada do sentencialismo por parte de Husserl é porque ele admitirá uma versão moderada do sentencialismo que começa justamente por rejeitar essa tese que seria o princípio nuclear da versão forte ou analítico-linguística da tese sentencialista. Está implícito nessa rejeição da tese linguística que deveremos ter algum outro modo independente de identificar pensamentos que não por meio simplesmente das sentenças que os expressam. Dessa maneira, uma versão moderada do sentencialismo seria tal que precisaria admitir não só que (i) a análise da estrutura de sentenças não esgota a estrutura do pensamento expressado, mas também que (ii) não há nada de implausível em conceber modos independentes de acesso alternativo ao teor de significação proposicional ou pensamento enunciado.

Na verdade, esse é o ponto de interesse no debate (que não cabe reconstituir aqui) sobre as dificuldades internas ao modelo analítico-linguístico de análise de pensamento, a saber, o ponto de que em algum estágio da análise parece se fazer necessário restringir o primado analítico da linguagem na abordagem do pensamento e introduzir um meio alternativo, ao menos relativamente independente, para a abordagem do pensamento (BELL, 1996). Apenas não vejo porque essa via alternativa teria de ser um modo de acesso ao pensamento de caráter direto, por meio simplesmente da percepção interna, e de modo completamente independente da linguagem. Ao atribuir a Husserl uma versão moderada do sentencialismo, tento justamente evitar essa disjunção exclusiva entre dois modelos de análise, de maneira a dar reconhecimento ao papel central da linguagem na análise fenomenológica da significação que se guia conjuntamente pela consideração sim das vivências de significação, mas apenas enquanto se efetuam nas enunciações concretas. Em suma, gostaria de chamar a atenção para o fato de que teríamos aqui, por assim dizer, um procedimento híbrido que se poderia considerar tanto como uma análise quasi-linguística do pensamento quanto, equivalentemente, como uma análise quasi-psicológica da significação, na medida em que tal análise decerto identificaria a significação com base nas enunciações, mas então apenas por meio da reflexão sobre a intenção efetuada no ato enunciativo. Mas como se daria exatamente essa análise fenomenológica da significação que, ao admitir meios relativamente independentes da linguagem para a identificação do

Rev. Filos., Aurora, Curitiba, v. 22, n. 31, p. 319-346, jul./dez. 2010 
pensamento, concebe então relações bem mais matizadas entre pensamento e linguagem? Devo na sequência expor como tal análise pode, de fato, ser implementada, mas não sem antes mostrar agora primeiramente que essa via de análise é aberta pelo entendimento de Husserl da "teoria da significação" como sendo um capítulo da "filosofia da lógica" antes que estritamente da "filosofia da linguagem".

Husserl ([1900a] 1992a, 4º Introdução, B295) concebe a teoria da significação como uma "morfologia pura das significações" ou uma "gramática puramente lógica", isto é, como "uma disciplina que investiga as estruturas primitivas das significações, as espécies primitivas de articulação interna e de ligação das significações, assim como investiga as leis, nelas fundadas, concernentes às operações de complexão e de modificação de significações" (HUSSERL, [1900a] 1992a, 4º $§ 14$, B336), segundo as quais é determinada a formação de efetivas unidades significativas por contraposição a meros agregados desconexos. A tarefa de uma tal disciplina parece, assim, poder ser concebida como equivalente a um programa sintático de formulação das regras de boa formação de expressões de uma linguagem. Observe-se inicialmente, porém, que o próprio Husserl repetidamente reafirma que suas análises se ocupam com categorias e relações lógicas que dizem respeito propriamente ao pensamento proposicional como tal e não simplesmente a formas linguísticas que podem lhe ser correspondentes. Por exemplo: "em todos os casos, nos quais nós usamos expressões gramaticais tais como predicação, proposições e outras do tipo, temos em vista exclusivamente a formação de significação correspondente" (HUSSERL, [1929] 1992c, Anexo I, p. 259; grifo meu. HUSSERL, [1939] 1985, §50b, p. 247, nota; p. 248; §53, p. 266). A equivalência, então, entre a gramática lógica de significações e a sintaxe de linguagens naturais parece, de fato, poder ter lugar desde que atentemos que a sintaxe lógica husserliana não pretende ser sintaxe "de uma" linguagem, mas sim "da" linguagem.

O ponto é que Husserl pretende fixar não regras de emprego de expressões de uma linguagem natural particular, mas sim categorias e leis da significação que toda e qualquer linguagem deve poder articular, se ela deve poder ser não um mero código auxiliar extrínseco de nossa comunicação, mas sim um meio próprio de expressão do pensamento. As formas de significação que serão objeto de análise da gramática lógica não são, então, primariamente formas linguísticas de alguma linguagem natural, mas antes são formas lógicas do pensamento categorial que devem, então, contar como determinantes das formas linguísticas de qualquer linguagem suficientemente rica para expressá-lo. 
As regras em questão são aquelas relativas a categorias de significações que uma linguagem não deve violar se suas formas linguísticas devem poder ser significativas, isto é, se suas formas linguísticas devem poder veicular o teor de significação categorialmente determinado do pensamento. Husserl ([1908] 1987, §22, p. 78) escreve:

o pensar discursivo ou categorial introduz sua profusão de formas, uma certa articulação, cada ato parcial categorial tem sua posição e função determinadas e, em conformidade com elas, tem sua forma determinada [...] O pensar lingüístico reflete todas essas articulações e formas nas representações das expressões [...] Em linguagens suficientemente desenvolvidas, deve naturalmente refletir-se na gramática da expressão as representações categoriais e suas formas e, portanto, às diferenças de representações quanto a seu conteúdo e forma devem corresponder diferenças das expressões gramaticais.

Husserl ([1900a] 1992a, 4º $§ 14$, B338) acredita ter razões para assumir "que a linguagem não apenas tem um fundamento fisiológico, psicológico e histórico-cultural, mas também tem um fundamento a priori", se é o caso que, mesmo no estudo das linguagens naturais, os linguistas devem poder chegar a reconhecer que "há também na esfera gramatical um padrão fixo, uma norma a priori que não pode ser transgredida" (HUSSERL, [1900a] 1992a, $\left.4^{\mathrm{o}}, \S 14, \mathrm{~B} 336\right)$. Com efeito, o fenômeno linguístico básico que deve suscitar a investigação gramatical consiste no fato de que, em toda linguagem, certas sequências de expressões são admitidas, enquanto outras sequências são simplesmente excluídas como ilegítimas. Ao diagnosticar as razões de tal fenômeno, Husserl vê a necessidade de destacar a atuação de regras gerais de formação determinando as sequências bem formadas de expressões de uma linguagem, regras estas que seriam, quanto ao essencial, a contraparte linguística de regras a priori dizendo respeito primariamente à compatibilidade de significações parciais de categorias determinadas na formação de unidades concretas de significações: "as incompatibilidades de caráter a priori em questão aqui encontram sua expressão gramatical [...] nas regras que governam as ligações gramaticais das partes do discurso" (HUSSERL, [1900a] 1992a, 4º,$\S 12$, B327-8). Mesmo a investigação gramatical de linguagens naturais particulares parece precisar pressupor que elas são também determinadas por fatores $a$ priori, por assim dizer, por "um arcabouço ideal que cada linguagem natural preenche e reveste de diferentes maneiras com material empírico e segundo 
motivos empíricos em parte casualmente variáveis e em parte concernentes às particularidades do humano em geral" (HUSSERL, [1900a] 1992a, 4º §14, B338), e isso até mesmo como uma condição da própria pesquisa gramatical:

É preciso levar em conta esse arcabouço ideal para se poder então perguntar significativamente: como a língua alemã, o latim, o chinês, e assim por diante, expressam 'a' proposição existencial, 'a' proposição categórica, 'a' proposição condicional, 'o' plural, 'as' modalidades do 'possível' e do 'provável', o 'não' e assim por diante? (HUSSERL, [1900a] 1992a, 4º §14, B339).

Husserl recusa como sendo até mesmo despropositada uma investigação gramatical que, assumindo serem as categorias de significações meras categorias linguísticas e não formas do pensamento categorial enquanto tal, pretenda então descrever sua gênese causal; nesse sentido, Husserl ([19171918] 1996, §21, p. 99) escreve: "não tem qualquer sentido perguntar como as categorias de significações [...] ou como as significações formais [...] se originaram. Pode-se apenas perguntar como os seres humanos têm chegado a expressá-las".

Por isso, Husserl ([1900a] 1992a, 4º $§ 14$, B340) argumenta que sua investigação deve servir "para tornar inteligível a essência ideal de toda linguagem enquanto tal", e isso não apenas porque cada linguagem natural em maior ou menor grau se conforma a essas determinações a priori, mas mais fortemente, e mesmo bem independentemente de investigações concretas de qualquer gramática comparativa das linguagens naturais, porque "não é concebível nenhuma linguagem que não seja essencialmente determinada também por esse a priori" (HUSSERL, [1900a] 1992a, 4º $§ 14, \mathrm{~B} 338$ ), isto é, porque o próprio conceito de linguagem compromete-nos com a assunção de categorias de significação, bem como de regras a priori, nelas fundadas, de formação de sequências linguísticas unitárias significativas. Há assim um primado fenomenológico e lógico das determinações relativas às significações do pensamento categorial diante das determinações simplesmente linguísticas, mas que não exclui, antes condiciona, uma estreita relação entre, por um lado, a morfologia das significações e, por outro lado, a gramática das linguagens naturais - afinal, as formas categoriais do pensamento discursivo são também determinantes das formas linguísticas que devem poder expressar propriamente pensamentos (HUSSERL, [1900a] 1992a, 4º §7, B310). Por reconhecer, contudo, que as linguagens naturais servem ainda a múltiplas funções e estão também sujeitas a determinações de várias outras ordens (HUSSERL, 
[1900a] 1992a, 4º $§ 14$, B336), Husserl sabe que não se pode pretender que haja uma exata correspondência entre formas linguísticas e formas categoriais do pensamento; em suma, as linguagens naturais não estão destinadas à mera expressão de relações objetivas do teor de significação proposicional ou pensamentos:

reconhecidamente, não são apenas as diferenças de significação que condicionam as diferenciações de expressões. Eu relembro aqui a diferenciação de matiz nas tendências estéticas do discurso" [...], assim como "distinções materiais de significação, com ampla utilidade comunicativa, imprimem-se nas linguagens naturais de um modo semelhantemente tão impositivo quanto o fazem as distinções lógicas básicas (a saber, as distinções que se fundam a priori na essência geral das significações) (HUSSERL, [1900a] 1992a, Introdução, §4, B13, B14; HUSSERL, [1917-1918] 1996, §15a, p. 66).

Sendo assim, não se pode conceber a análise de significações como consistindo simplesmente em uma análise do comportamento de expressões linguísticas com suas regras convencionais de emprego e, portanto, não se pode querer derivar as formas categoriais do teor de significação do pensamento diretamente de formas linguísticas dadas para sua expressão.

As reservas de Husserl diante da análise direta e independente tanto da linguagem quanto do pensamento na especificação do teor de significação proposicional parece decorrer então da ponderação completamente sensata acerca da disparidade a ser levada em conta entre, por um lado, o caráter estritamente conceitual ou categorial do teor de significação do pensamento e, por outro lado, o caráter multifuncional da linguagem enquanto instituição social que, por assim dizer, serve a múltiplos senhores ou, mais precisamente, serve a diferentes fins, tanto aos fins mais práticos da interação humana quanto aos fins estéticos mais sublimes, sem esquecer que com isso a linguagem não deixa de também poder continuar servindo ao fim propriamente cognitivo de chegar a dar articulação expressiva apropriada ao pensamento que intenta apreender conceitualmente, de maneira adequada, o estrato elementar da experiência do mundo, e isso segundo a generalidade e objetividade próprias ao pensamento discursivo (cf. e.g. o $§ 124$ da obra Ideias I de 1913). Por isso, o admitido paralelismo, dependência ou isomorfia entre pensamento e linguagem deve ser tomado cum grano salis e o sentencialismo deve ser admitido apenas em uma versão moderada, como o próprio Husserl não deixa recorrentemente de enfatizar, tal como na seguinte passagem: 
Se usamos uma sentença enunciativa em uma linguagem desenvolvida por exemplo: 'o rei, que retornou de sua viagem, reassumiu a condução do governo'-, então, pelo menos até certo ponto, reflete-se na estrutura e formação lingüística uma certa estrutura e formação da vivência doadora de sentido. Eu digo: 'até certo ponto', e enfatizo simultaneamente que falar aqui de um 'refletir-se' é apenas metafórico (HUSSERL, [1917-1918] 1996, p. 66; grifo meu).

O que parece a Husserl problemático, ou pelo menos metafórico, seria a concepção de que a estrutura de enunciados "reflete" estritamente, ou perfeitamente, a estrutura de pensamentos, de modo que, como no sentencialismo forte, aquelas estruturas das sentenças poderiam então ser assumidas como modelo de nossa análise do teor de significação do pensamento enunciado. Enunciados até refletem, mas apenas "até certo ponto", a estrutura das significações proposicionais que expressam.

Parece claro que, com isso, Husserl quer indicar que é pelo menos possível, para não dizer provável, que partes próprias de uma significação proposicional não se deixem descobrir apenas com base na consideração da forma do enunciado que a expressa, e isso não necessariamente porque as partes do enunciado não tenham correspondência nas partes da proposição expressa, mas talvez, inversamente, porque partes da proposição em questão podem restar ai simplesmente inexpressadas, não lingüisticamente articuladas e, às vezes, nem sequer pensadas, ainda que integrem o teor de significação proposicional próprio à enunciação em questão. Sendo assim, Husserl pode conceber que os sentidos das partes de um enunciado sejam necessariamente partes do pensamento expresso pelo enunciado, sem por isso estar comprometido com a tese, mais forte, de que a forma de um enunciado revelaria suficientemente a estrutura do pensamento e, assim, de que ela ofereceria um modelo de análise exaustiva do pensamento enunciado. Mas como então chegar a uma determinação do teor de pensamento completamente determinado a partir de uma análise da significação que não superestime nem subestime o papel da linguagem? Trata-se, nesse caso, de chegar a determinar o teor proposicional expresso, de fazer juízos sobre a significação própria de enunciados, mas sempre por meio da análise do que se patenteia fenomenologicamente em vivências do que o enunciado quer dizer. Como fazer isso?

Quando se trata da análise fenomenológica do fenômeno da significação, não há dúvida de que a vivência a ser considerada é a vivência concreta da expressão animada de sentido (HUSSERL, [1900a] 1992a, 1º, §9, B37), 
vale dizer, a vivência de compreensão que é própria ao emprego e apreensão de signos significativos, aliás, que é própria a enunciados (ainda que isso ocorra "na vida solitária da alma", vale dizer, no pensamento discursivo que não tem propósito comunicativo mesmo quando é eventualmente proferido). A reflexão que dá acesso a significações pode ser entendida como uma consideração do que querem dizer as expressões usadas ou apreendidas com compreensão ao se falar normalmente sobre o curso das coisas e que apenas são expressões aptas para tanto, na medida em que a essas expressões típicas pertencem típicas intenções de significação que são aquelas que os falantes já sempre efetuaram irrefletidamente se é o caso que a ocorrência da expressão é significativa, vale dizer, se é o caso de a expressão estar sendo usada ou apreendida com compreensão.

A reflexão em questão, tal como pretende Husserl, pode então se processar como uma consideração das intenções de significação que nós próprios efetuamos ao usarmos e apreendermos com compreensão as expressões linguísticas, o que depende então de efetuarmos tal intenção de significação não mais em um emprego ou apreensão irrefletidos de tais expressões, mas antes a efetuarmos em uma atitude reflexiva interessada em especificar clara e distintamente todos os constituintes do que tais expressões não podem deixar de querer dizer literalmente. $\mathrm{O}$ exame reflexivo de significações é, então, um exame propriamente daquilo que inevitavelmente pensamos em certos enunciados, do nosso pensamento na acepção objetiva de teor de significação proposicional completamente determinado de atos expressivos; e esse exame, apenas impropriamente, é um exame da simples forma e regras linguísticas das sentenças que expressam esses pensamentos, ainda que o exame do pensamento não se processe independentemente da consideração do emprego ou apreensão com compreensão dessas sentenças. Significações não são objetos primários de atenção, mas são antes a espécie (ou atributo disposicional) daqueles nossos atos que consistem em ser um meio determinado de conceber certa objetalidade e, assim, que têm o papel psicológico de ser capazes de determinar a referência objetal do ato (o tema do pensamento, por assim dizer) e, por conseguinte, da expressão apta a manifestar esse ato. A tematização de significações deve, então, consistir em uma reflexão (e em uma abstração ideativa) sobre o que é próprio às intenções de significação de atos expressivos concretos.

Mas como exatamente devemos poder chegar a discriminar o que pertence à típica intenção de significação própria a um enunciado? As evidências que devem tanto motivar quanto justificar nossos juízos acerca de 
significações não são, então, simplesmente evidências linguísticas sobre as formas e comportamentos das expressões da linguagem natural que conhecemos, mas também não são simplesmente evidências introspectivas sobre os estados mentais ocorrendo em nossa consciência, nem tampouco evidências sobre os objetos de referência eventualmente dados intuitivamente. Husserl pretende poder discriminar um tipo de evidência concernente puramente às nossas intenções de significação em enunciações, evidência esta que deve estar na base de nossas formulações e avaliações dos juízos acerca das partes conteudísticas e da estrutura formal e, por conseguinte, acerca do teor de significação ou pensamento expressado, a saber, o que ele chamará de "evidência concernente à nitidez" (em alemão, Evidenz de Deutlichkeit, HUSSERL, [1929] 1992c, §16a).

Intenções de significação, vale dizer, atos que efetuamos como condição necessária de expressões ocorrerem significativamente, podem realizarse ou bem de maneira vaga, imprecisa, indistinta ou bem de maneira nítida, precisa, distinta. $O$ caráter ou bem vago ou bem nítido de uma intenção de significação proposicional ou juízo não diz respeito ao seu grau de satisfação intuitiva, isto é, ao seu grau de evidência concernente a sua clareza (em alemão, Evidenz der Klarheit, HUSSERL, [1929] 1992c, §16b), mas antes diz respeito simplesmente a quão explicitamente as suas intenções parciais constitutivas são também expressamente efetuadas, de tal modo que Husserl ([1908] 1987 , §39) poderá descrever a passagem de um modo de efetuação vago de um juízo para seu modo de efetuação nítido como consistindo na passagem a "uma efetuação explícita e articulada dos membros estruturais e das formas categoriais" do mesmo juízo anteriormente efetuado de modo vago, isto é, de um modo que, por assim dizer, não efetuava exaustivamente cada um dos atos parciais concernentes a seus membros e a sua estrutura formal.

Esse procedimento de explicitação, baseado na consideração do que nos é dado como a significação a partir da efetuação nítida ou distinta de cada uma das intenções de significação parciais integrantes de um ato expressivo determinado, é descrito por Husserl, no §20 da obra Ideen III ([1912] 1986), como uma "explanação" (Verdeutlichung) da significação de expressões por contraste com o que ele chama de "clarificação" (Klärung). Embora Husserl tome em conta então exemplarmente o significado de expressões subproposicionais, o contexto deixa claro que ele intenciona que esses dois distintos modos de esclarecer significações (e, na verdade, duas etapas sucessivas nesse esclarecimento) valham para significações complexas em geral. A explanação (Husserl usa também o termo Explikation, melhor entendido na acepção de 
“explicitação"), como a primeira etapa de um esclarecimento de significações, tem a forma de uma análise: "antes de darmos qualquer passo na direção da clarificação [...] 'pode ser ponderado' o que jaz 'na intenção'; por exemplo, em 'decaedro' [jaz]: um sólido, um poliedro, ser regular, ter dez faces congruentes” (HUSSERL, [1912] 1986, §20, p. [103]).

Assim apresentada, a explanação de uma significação parece consistir em um tipo de reflexão sobre nossa compreensão informal, aliás, irrefletida de alguma expressão linguística (no exemplo, da expressão "decaedro"). Tal reflexão resultaria na especificação dos elementos (no caso em questão, "um sólido", "um poliedro", etc.) que formam o conteúdo (Husserl fala aqui em Denkstoff) do que é literalmente pensado com a expressão em questão, isto é, tal reflexão deve nos levar a explicitar "o que é intencionado com a expressão" em questão (HUSSERL, [1912] 1986, §20, p. [103]). De fato, Husserl caracteriza a explanação como "uma análise de sentido de caráter lingüístico" (HUSSERL, [1912] 1986, §20, p. [102]) e diz que ela é "um procedimento que se executa internamente à mera esfera do pensamento" (HUSSERL, [1912] 1986, p. [101]). Ao proceder a essa reflexão sobre o que é intencionado sem mais quando se usa com compreensão uma expressão linguística, cabenos especificar as significações parciais que formam o teor de pensamento típico da compreensão da expressão típica correspondente, de maneira que obtemos, por assim dizer, uma lista de significações parciais que integram a significação completa.

Pode-se considerar, porém, que é aqui pouco determinado o modo exato como devemos proceder para realizar essa reflexão sobre nossa compreensão irrefletida de uma expressão linguística, vale dizer, sobre a típica intenção de significação própria a uma expressão típica. Uma indicação mais precisa desse procedimento de explanação de um conceito, aliás, de uma significação pode ser extraída da seguinte afirmação: "Nós partimos então de exemplos que exibem uma indubitável aplicação da palavra" (HUSSERL, [1912] 1986, $\S 19$, p. [100]). Trata-se, então, de partir da consideração de exemplos de uso da expressão cujo teor significacional, ou conceito correspondente, cabe ser esclarecido. Husserl não diz então quais tipos de exemplos de uso de expressões seriam aqui relevantes, mas podemos supor que pelo menos um tipo de emprego de expressões deve ser considerado, nomeadamente, aquele emprego, por exemplo, de "decaedro" com a função de diretamente caracterizar um objeto referido por um termo singular: " $b$ é (não é) um decaedro" ou "isto é (não é) um decaedro". Parece que se espera que sejamos capazes de dizer sob quais condições estamos dispostos a caracterizar algo como "decaedro" e sob quais 
condições estamos dispostos a negar a algo tal caracterização. Parece que se espera, enfim, que com base em um exemplo (ou em um apropriado número de exemplos) da forma " $b$ é (não é) um decaedro", possamos chegar a dizer: " $b$ é (não é) um decaedro, porque $b$ é (não é) F, G, H”, de maneira que, assim, possamos chegar a constatar que pelo menos as propriedades de ser um $\mathrm{F}$, um $\mathrm{G}$, um $\mathrm{H}$ seriam conceitos próprios ao teor significacional do que é literalmente intencionado ao se usar a expressão assim explicitada.

De todo modo, Husserl indica que, com essa etapa explanatória do esclarecimento, apenas explicitamos os elementos constituintes, enfim, os conceitos ou significações parciais que integram o conteúdo da intenção de significação que corresponde ao teor de significação próprio das expressões linguísticas em questão, sem recorrer ainda a intuições possíveis que reforçariam, confirmariam ou mesmo frustrariam e imporiam talvez uma revisão do que supúnhamos ser a intenção de significação em questão, e isso, por exemplo, ao tornar efetivamente presente o que é aí intencionado, o que seria, em certa medida, tarefa justamente daquela mencionada clarificação da significação enquanto etapa complementar de seu esclarecimento. Essa caracterização da natureza da explanação da significação de expressões como sendo independente da consideração das condições de satisfação intuitiva da intenção de significação em questão e como se baseando na nossa mera compreensão simbólica, isto é, na nossa mera efetuação da intenção de significação própria a uma expressão, pode ser reencontrada ao longo da obra de Husserl. Por exemplo, ele afirma: "com efeito, uma consciência não-preenchida inarticulada pode ser convertida em uma 'correspondente' consciência não-preenchida com uma articulação interna, de modo que (pelo recobrimento identificador caracterizável como 'explicitação' [Explikation]) o teor de sentido indistintamente intencionado se 'desdobra em seus constituintes' como 'o explicitado' [das Explikat], como a significação [Meinung] própria do teor unitário anteriormente indistinto" (HUSSERL, [1929] 1992c, §16-a, p. [51]; cf. também p. [52]). Podemos ler ainda o seguinte: “essa explanação é integralmente possível internamente à consciência não-preenchida. Isso quer dizer que o que é intencionado no juízo não precisa ser dado intuitivamente e que é suficiente efetuar nitidamente a mera intenção do juízo" (HUSSERL, [1939] 1985, §26, p. 142-3). ${ }^{3}$

3 Nesse contexto, Husserl falará dessa forma de esclarecimento como "explanação analítica" e a tratará como um caso particular de "explicitação", nomeadamente, como "explicitação no âmbito da consciência desprovida de preenchimento", vale dizer, meramente simbólica ou signitiva ([1939] 1985, p. 142). Depreende-se daí que "explicitação" será o termo genérico para 


\section{Considerações finais}

Por tudo isso, parece certo que sem recorrermos reflexivamente ao que é tipicamente pensado em um enunciado, isto é, sem recorrermos à intenção de significação que é tornada explícita no modo de efetuação não vago, mas antes distinto ou nítido do ato que é tipicamente manifestado quando se emprega com compreensão um enunciado, sem isso, enfim, não podemos entender o caráter mais peculiar da análise fenomenológica da significação, a saber, esse seu caráter bastante ordinário de nunca tomar em separado nem o pensamento nem a linguagem ao tentar esclarecer o teor de significação proposicional expressado, ou, em outras palavras, ao especificar o que uma enunciação quer dizer. Um juízo vago manifestado em uma enunciação seria, assim, aquele que não deixa ver expressamente - vale dizer, que apenas deixa implícita e não articulada - sua estrutura interna, isto é, seus membros e a forma de conexão deles. Husserl ([1908] 1987, §39, p. 132) afirma:

no caso da efetuação de um ato predicativo, podemos [...] efetuar apenas vagamente o pensamento proposicional completo, a saber, efetuá-lo sem a articulação certa [...] Eu posso ter uma crença e, todavia, efetuar o juízo não de modo plenamente apropriado, a saber, não segundo todos os seus atos parciais, segundo todos os sub-posicionamentos e posicionamentos aí pertinentes, nem segundo os posicionamentos supostos e os posicionamentos conseqüentes. Há [...] um julgar não-nítido. As interconexões lingüísticas são suportes de atos de significação vagos e de interconexões vagas de atos, acerca das quais é bem difícil dizer se elas têm a composição que é aí 'requerida', pois variados posicionamentos parciais não são de modo algum efetuados e têm lugar então apenas um vago entendimento unitário [das interconexões lingüísticas empregadas] (...).

Uma ilustração simples dessa situação é oferecida por aqueles casos em que julgamos que algum objeto real tem certa propriedade e deixamos então implícita, ou assumida sem mais, a determinação temporal ou espacial

todo processo de desdobrar em uma articulação nítida algo intencionado inarticuladamente. Note-se ainda que Husserl fala aqui da explanação como correspondendo à efetuação de um ato de julgar explícito, no qual a intenção judicativa antes inarticulada é efetuada agora nitidamente. Ele também justifica essa possibilidade metódica de explanação em função do caráter de "intencionalidade fundada" próprio aos atos de julgar, de maneira que devemos, então, conceber a explanação como o procedimento de tornar explícitos os conteúdos intencionais dos atos parciais que fundam o ato de julgar complexo. 
que é necessariamente parte da proposição determinada que veiculamos e que o contexto contribui então para especificar. Por exemplo, se dizemos: "o conhecimento não é considerado como tendo um valor intrínseco", está claro que estamos falando também de algum local e tempo em que isso é o caso, de modo que apenas se chega aí a compreender algo de completamente determinado sob a assunção tácita, apoiada no contexto de enunciação, de tal significação "implícita" ou "inarticulada" concernente a uma demarcação espacial e temporal, na qual nem precisamos pensar, mas que integra sem mais o teor de significação proposicional expresso (não é possível aqui dizer mais sobre essa indexicalidade "oculta" da significação dos enunciados empíricos em geral, que foi analisada pioneiramente por Husserl partindo do caso mais restrito de expressões dêiticas ou sistematicamente dependentes do contexto de enunciação, as quais são decisivas para patentear a diferença entre o teor de significação proposicional ou pensamento e a mera regra convencional de emprego de expressões ou significação linguística; cf. HUSSERL, [1900a] 1992a, 1º capítulo 3).

Porém, nossos juízos sobre o teor de significação proposicional próprio a um enunciado não são juízos que podem justificar-se apenas com base na efetuação desse ato proposicional em um modo vago, que não deixa ver nitidamente suas partes e articulações constitutivas, mas antes requer que efetuemos de modo explícito tal ato proposicional, isto é, que efetuemos conjuntamente todos e cada um dos seus atos parciais constitutivos. Husserl afirma:

uma espécie de doação se consuma sob o título de significação, apenas na medida em que a forma da configuração categorial [...] chega à efetiva doação através da circunstância de que as sínteses categoriais, os atos categoriais são efetivamente efetuados. Essa efetiva efetuação tem o caráter de uma espécie de intuição (HUSSERL, [1908] 1987, §39, p. 133).

A doação originária, isto é, a identificação inequívoca da própria significação proposicional determinada, tem lugar, então, não necessariamente em um preenchimento intuitivo dessas intenções de significação, o qual apresentaria diretamente a objetalidade ordinariamente intencionada, mas antes essa doação da significação consiste simplesmente em uma efetuação tal do ato proposicional que deixa ver todas as capacidades conceituais manifestadas na enunciação, isto é, que não mais deixa implícita qualquer de suas intenções de significação parciais e que, assim, pode servir de base para a atitude reflexiva dirigida para o teor significacional de cada um de todos os atos 
que integram e contribuem para o teor de significação do ato proposicional manifestado no enunciado. Husserl explica:

trata-se de proposições, e enquanto proposições, enquanto essas unidades ideais idênticas, elas nos são dadas com base na mera compreensão do enunciado e segundo uma apropriada perspectiva e uma correspondente efetuação nítida do pensamento. Essa é uma nova perspectiva com um novo tipo de doação [intuitiva], pois o que nós vemos aí, o que aí nos é dado, o que nós analisamos então quanto a sua gramática [...] é justamente a mera proposição (HUSSERL, [1908] 1987, §38, p. 131).

A efetuação nítida de uma intenção de significação em todas as suas articulações torna, então, explícito seu próprio teor de significação proposicional ou pensamento completamente determinado e, assim, é o que nos permite tematizar reflexivamente as próprias significações e fazer juízos sobre seus conteúdos integrantes, suas formas próprias e suas relações (de identidade, de consistência, de implicação, de contradição, etc.) com outras significações:

Na medida em que trazemos a proposição a uma doação nítida, podemos agora desmembrá-la, ligá-la a outras proposições, podemos dizer verdades acerca de proposições, em suma, podemos empreender uma gramática pura como uma morfologia de proposições, de partes possíveis de proposições e de complexões de proposições (HUSSERL, [1908] 1987, §38, p. 130).

Tendo assim caracterizado a análise fenomenológica do teor de significação proposicional ou pensamento em uma estratégia de análise híbrida, nem exclusivamente linguística, nem exclusivamente psicológica, vemos Husserl anunciar nessa passagem a possibilidade de, sobre essa base concreta de análise, implementar então seu projeto geral de uma morfologia das significações, de especificação de suas regras de formação e de modificação, em suma, de uma gramática puramente lógica da significação enquanto tal, aliás, do elemento categorial do pensamento na acepção objetiva, tal como ele projetara e iniciara na quarta de suas Investigações lógicas. Porém, desse ponto não me cabe mais tratar aqui. 


\section{Referências}

APEL, K.-O. Die beiden Phasen der Phänomenologie in ihrer Auswirkung auf das philosophische Vorverständnis von Sprache und Dichtung in der Gegenwart. In: APEL, K-O. Transformation der Philosophie, I. Frankfurt AM: Suhrkamp, [1955] 1973. p. 79-105.

DUMMETT, M. The philosophy of thought and philosophy of language. In: VUILLEMIN, J. (Ed.). Mérites et limites des méthodes logiques en philosophie. Paris: Vrin, [1984] 1986. p. 155-163.

DUMMETT, M. Origins of analytical philosophy. Cambridge, MA: Harvard University Press, 1993.

BELL, D. Husserl. London: Routledge, 1990.

BELL, D. The formation of concepts and the structure of thoughts. Philosophy and Phenomenological Research, v. 66, n. 3, p. 583-596, 1996.

BENOIST, J. Husserl's theory of meaning in the first logical investigation. In: DAHLSTROM, D. (Ed.). Husserl's logical investigations. Dodrecht: Kluwer, 2003.

DE PALMA, V. Husserls phänomenologische Semiotik. In: MAYER, V. (Ed.). Husserls logische Untersuchungen. Berlin: Akademie Verlag, 2008. p. 43-51.

HUSSERL, E. Logische Untersuchungen, II/I: $1^{\circ}-5^{\circ}$ Untersuchungen zur Phänomenologie und Theorie der Erkenntnis. Hamburg: Felix Meiner, [1900a] 1992a. Gesammelte Schriften 3, segundo o texto de Hua XIX/1.

HUSSERL, E. Logische Untersuchungen, II/II: $6^{\circ}$ Untersuchung zur Phänomenologie und Theorie der Erkenntnis. Hamburg: Felix Meiner, [1900b] 1992b. Gesammelte Schriften 4, segundo o texto de Hua XIX/2.

HUSSERL, E. Vorlesungen über Bedeutungslehre. Dordrecht: Kluwer, [1908] 1987. Hua XXVI.

HUSSERL, E. Die Phänomenologie und die fundamente der Wissenschaften. Hamburg: Felix Meiner, [1912] 1986. Texto parcial de Hua V: Ideen III.

HUSSERL, E. Logik und allgemeine Wissenschaftstheorie. Dordrecht: Kluwer, [1917-1918] 1996. Hua XXX.

HUSSERL, E. Formale und transzendentale Logik. Hamburg: Felix Meiner, [1929] 1992c. Gesammelte Schriften 7, segundo o texto de Hua XVII. 
HUSSERL, E. Erfahrung und Urteil. Hamburg: Felix Meiner, [1939] 1985.

ROLLINGER, R. Names, statements, and their corresponding acts. In: FISETTE, D. (Ed.). Husserl's logical investigations reconsidered. London: Kluwer, 2003. p. 133-150.

SOLDATI, G. Die Objektivität der Bedeutung. In: MAYER, V. (Ed.). Husserls logische Untersuchungen. Berlin: Akademie Verlag, 2008. p. 61-75.

SOLDATI, G. Bedeutung und psychicher Gehalt: zur sprachanalytischen Kritik von Husserls früher Phänomenologie. Paderborn: Ferdinand Schöning, 1994.

TEIXEIRA, D. Significado enquanto atributo de intenções nas Logische Untersuchungen de Husserl. In: LOPARIC, Z; WALTON, R. (Ed.). Phenomenology 2005: selected essays from Latin America, II. Bucharest: Zeta Books, 2007. p. 585-616.

TUGENDHAT, E. Phenomenology and linguistic analysis. In: ELLISTON, F.; MCCORMICK, P. (Ed.). Husserl: expositions and appraisals. Notre Dame: University of Notre Dame Press, [1970] 1977. p. 325-337.

WELTON, D. The origins of meaning: a critical study of the thresholds of husserlian phenomenology. Boston: Kluwer, 1983.

Recebido: $20 / 07 / 2010$

Received: 07/20/2010

Aprovado: 15/09/2010

Approved: 09/15/2010 